\title{
Implicaciones éticas del reconocimiento de los pueblos originarios en El Salvador. Una propuesta desde la interculturalidad
}

The ethical implications in the acknowledgment of the indigenous peoples in El Salvador. An intercultural proposal

\author{
René Antonio Chanta-Martínez \\ Docente \\ rene.chanta@aol.com \\ http://hdl.handle.net/11298/407 \\ Recibido: 21/07/17 - Aceptado: 20/10/17
}

"Todo aprendizaje exige este viaje hacia el otro, hacia la alteridad",

Michel Serres (1991)

\begin{abstract}
Resumen
El presente artículo pretende ser una aproximación a las implicaciones éticas que tendría el reconocimiento de los pueblos originarios en El Salvador. Históricamente, los pueblos originarios han sido marginados e incluso invisibilizados por parte de las políticas públicas estatales. Últimamente en El Salvador se ha reformado el artículo 63 de la Constitución de la República, lo cual podría verse como un avance en el reconocimiento de este sector. Sin embargo, aún no ha sido ratificado el Convenio 169 de la Organización Internacional del Trabajo (OIT), siendo aún una deuda con los pueblos indígenas. Ante esto, este estudio propone el enfoque de la filosofía de la interculturalidad como un medio para profundizar y conocer a estas culturas originarias. Desde allí se lanzarán algunas implicaciones éticas que orientarían acciones concretas para avanzar en el reconocimiento de este sector de la población salvadoreña.
\end{abstract}

\section{Palabras clave}

Grupos étnicos - El Salvador; Relaciones étnicas El Salvador; Intercambio cultural - El Salvador; Historia El Salvador

\section{Abstract}

This article expects to be an approximation to the ethical implications that the recognition of the indigenous peoples of El Salvador could have. Historically speaking, the Native peoples have been marginalized and even made invisible by the state public policies. Lately, art. 63 of the Republic Constitution has been amended; this could be seen as an advancement towards the recognition of these peoples. However, Agreement 169 from the International Labor Organization (ILO) has not been ratified yet, thus representing a debt towards the indigenous peoples. Given this situation, this study is proposing to take the approach of cultural exchange as a means to deepen into the knowledge of these native cultures. From it, some ethical implications will be raised in order to lead to concrete action for the advancement in the recognition of this sector of the Salvadorean population.

\section{Keywords}

Ethnic groups - El Salvador; Ethnic relations - El Salvador; Cultural exchange - El Salvador; History - El Salvador 
Hablar de pueblos originarios en El Salvador es referirnos a culturas no mayoritarias, no hegemónicas, pero que sí son nacionales por ser parte de la diversidad existente en nuestro territorio. No es un secreto que, durante buena parte de la historia nacional, dichos grupos hayan sido marginados e inclusive invisibilizados. Dicha situación ha traído consecuencias negativas para estos grupos y ha sido uno de los obstáculos para lograr una auténtica convivencia y cohesión nacional.

Sin duda, hoy en día hay varios autores que han abordado el tema de los pueblos originarios desde diferentes perspectivas y enfoques. En las Ciencias Sociales han habido aportes bastante ingentes sobre esta temática (Stavenhagen, 2010). La Filosofía no se ha quedado atrás y muestra puntos interesantes de diferentes culturas. Resaltan los estudios, en México, de Carlos Lenkersdorf sobre la cultura tojolabal en Chiapas (Lenkensdorf, 2005). O los textos de Miguel León-Portilla sobre los antiguos pueblos mexicanos (León Portilla, 2005). No obstante, en El Salvador, con excepción de las investigaciones que se hacen desde la Antropología, son escasos los estudios concretos de otras disciplinas que se refieran a este sector de la población. Es por eso que es pertinente que diferentes ciencias y disciplinas académicas se tomen en serio el papel de reflexionar sobre los pueblos originarios y aportar orientaciones de solución a sus diferentes problemáticas. El presente ensayo pretende analizar de manera sucinta las implicaciones éticas del reconocimiento de los pueblos indígenas salvadoreños. No está de más advertir que este escrito hará referencia al multiculturalismo, concepto que ha cobrado una vital relevancia en el ámbito académico y político para tratar la diversidad étnica y cultural dentro de los modernos Estados nación. También es necesario advertir que se propondrá una orientación de solución a la marginación y no reconocimiento en que se han mantenido los pueblos originarios en El Salvador desde la ética. Dicha solución tendrá como base los conceptos de interculturalidad y de ética dialógica en donde se enfatizará que hoy es necesario realizar un diálogo entre las culturas para conocerse y reconocerse mutuamente, siendo este un punto de partida para avanzar en los derechos de los pueblos originarios. $^{2}$

\section{El tratamiento a la diversidad cultural: un reto para todas las naciones}

Aunque cada país es distinto y tiene una historia peculiar, no cabe duda de que una de las circunstancias a las que tendrán que enfrentase tarde o temprano es el tratamiento a la diversidad cultural. Así, ante esta diversidad, un país en general podría tomar dos grandes caminos:

a) No abordar la diversidad cultural existente y creer que la sociedad es monocultural. Esto traería en principio graves consecuencias, ya que se pretenderá homogenizar culturalmente a todo un país negando, invisibilizando o disminuyendo las diferencias culturales. 0 bien, esto daría pie para que un grupo dominante se imponga sobre las otras culturas existentes en un territorio.

b) Contrario a lo anterior, el segundo camino se enfocaría básicamente en abordar la diversidad cultural presente en un territorio. Aquí existiría una amplia gama de acciones que podría tomar un país para abordar dicha diversidad. No es este el espacio para hacer referencia a las múltiples posibilidades de acción de un país sobre la pluralidad cultural de su territorio. Más bien, aquí nos centraremos en dos grandes posturas: el multiculturalismo y la interculturalidad.

\section{No abordar las diferencias culturales. Una invisibilización de los pueblos originarios}

En varios países, las diferencias culturales no han sido lo suficientemente tratadas o valoradas a pesar de la existencia de una gran diversidad de culturas en varios territorios. Poniendo como ejemplo a Europa, en muchos de sus países podemos encontrar diversos grupos culturales producto de múltiples factores, como la migración. Esto ha ido poco a poco tomando conciencia de muchas instancias locales y regionales que hablan de los derechos de las minorías. (Matterlat, 2009). También, América Latina es diversa, multiétnica y plurilingüe. En efecto, en el continente americano hay culturas indígenas, afroamericanas y también la vertiente criolla en la población. Sin embargo, históricamente ha habido la tendencia a negar dicha diversidad a tal punto que una cultura se impone sobre las demás.

\footnotetext{
2 En El Salvador ciertamente se ha dado un avance en relación con el reconocimiento de los pueblos indígenas en el país, pues en el año 2014 se reformó el artículo 63 de la Constitución de la República, añadiendo un párrafo sobre los pueblos originarios. Sin embargo, el país todavía no ha ratificado el Convenio 169 de la OIT en donde se enfatiza que los pueblos originarios tienen derecho a un territorio.
} 
Lo anterior deriva de no dar un tratamiento apropiado a la diversidad cultural. Esto podría deberse a prejuicios o ideas erróneas sobre los grupos originarios; también puede ser que esté ligado a intereses de ciertos sectores. En ese sentido, varios han visto la diversidad como una amenaza o peligro para la unidad o cohesión de un pueblo o nación. De esta manera, lo que se hace es homogenizar la cultura, intentando con esto esconder los particularismos o las diferencias. Así, podríamos poner múltiples ejemplos en la historia en donde se ha dado un aplastamiento a la diversidad (Rodriguez Gonzalez, 2003). Uno notable es el de la España de Franco, donde se dio una represión lingüística con el fin de que el castellano fuera la única lengua oficial del país. Con esto lo que en realidad se daba era una invisibilización de otras expresiones lingüísticas, como el catalán y el gallego. También, en América Latina, un grupo por lo general se siente el dominante y se impone a las demás culturas. En el caso de naciones como Guatemala, a pesar de tener una población indígena mayoritaria, la cultura criolla ha ejercido el poder dominante y ha invisibilizado a los grupos indígenas, creándose a la larga un fuerte racismo que se manifiesta en múltiples ámbitos de la sociedad (Casaús, 2010).

Se podría afirmar que la marginación y discriminación de los indígenas ha sido una constante en los modernos Estados nación latinoamericanos. En efecto, algunos estudios han dicho que la Independencia fue un proyecto criollo en donde el indígena tuvo poco que ver; y no apareció en los primeros discursos oficiales. Sobre esto Rodofo Stavenhagen manifiesta que,

aunque las repúblicas independientes —salvo excepciones- proclamaron ampliamente la igualdad de todas las personas ante la ley y concedieron derechos ciudadanos a todos los nacionales, incluyendo a los indígenas, éstos siempre han sido considerados y tratados como ciudadanos de segunda. Su exclusión social y política coincidió con su marginación económica y encapsulamiento cultural (Stavenhagen, 1999, p. 24).

Posteriormente, en la configuración de los Estados/ Nación modernos, los indígenas nuevamente fueron invisibilizados a lo largo del siglo XIX, ya que las élites mestizas se fueron haciéndose con el poder político y económico. De esta manera, podríamos decir que los nuevos Estados surgieron sin una política concreta que permitiera reconocer a los pueblos originarios. En el caso salvadoreño, resalta la situación de la extinción de las propiedades comunales y ejidales en 1881. Con esto se les quitaba a los pueblos indígenas la tierra, que era su medio principal de subsistencia.

También, de acuerdo con referencias, algunos intelectuales manifestaban un cierto racismo a la hora de hablar del indígena en El Salvador. Un ejemplo de esto es el historiador David Joaquín Guzmán. En sus escritos llega a manifestar que los indios son de semblante angular sin simetría en la forma y que solamente el espíritu liberal y humanitario de las instituciones puede ayudar a que el indígena sea instruido en la fe republicana y en la moral cristiana. Sin duda, las ideas de Guzmán estaban influidas por el positivismo que veía a la historia de la humanidad troquelada por la idea del progreso (Cortez, 2016, p. 46).

Posteriormente, en el siglo $\mathrm{XX}$, varios académicos hicieron referencia a que el indígena fue afectado por los acontecimientos de 1932, pues el Estado realizó sistemáticamente una matanza de indígenas y campesinos. De hecho, algunas referencias prefieren hablar de genocidio al referirse a este hecho en la región occidental del país (Martínez, 2012). Por otra parte, hay dificultades al momento de aproximarse a los pueblos originarios en el país. En primer lugar, el indígena salvadoreño se identifica poco con sus vestimentas tradicionales, y en segundo, por lo general no habla su lengua nativa. Según un estudio (UnescoConcultura, 2005), esto podría deberse a varios factores, entre los que se suele mencionar los siguientes:

a) El etnocidio de 1932, lo cual afectó grandemente a la población indígena del occidente del país.

b) El mestizaje, que pudo favorecerse por la pequeñez territorial del país.

c) El olvido de los pueblos originarios por parte de los gobiernos de turno.

No obstante, haciendo una especie de exploración de la influencia indígena en el país, a lo largo del territorio salvadoreño se pueden evidenciar tres grupos: a) los nahuapipiles, ubicados en las zonas occidental y central del país, b) los lencas, que se encuentran en la zona oriental y c) los cacaoperas, ubicados en el departamento de Morazán (Lemus, 2011). De estos tres grupos, en el occidente y centro del país es donde persiste la mayor parte de la población con rasgos indígenas. En el caso de las lenguas de estos grupos, la lenca ya despareció; y solamente en 
occidente hay algunos nahuahablantes. Esto de entrada es un problema para el investigador social y a menudo son confundidos con los campesinos.

A nivel constitucional, se podría decir que El Salvador no reconoció a los pueblos originarios. En efecto, las Constituciones olvidaron este tema a tal punto que bien podría hablarse de una invisibilización de los indígenas durante los siglos XIX y XX. Hubo que esperar hasta el siglo XXI para que fuera reformado el artículo 63 de la Constitución de la República. Dicha reforma había iniciado con la legislatura de 2012 y fue ratificada por la siguiente Asamblea Legislativa en el año 2014. Ahí se estableció que "El Salvador reconoce a los pueblos indígenas y adoptará políticas a fin de mantener y desarrollar su identidad étnica y cultural, cosmovisión, valores y espiritualidad" (Constitución El Salvador, artículo 63). ${ }^{3}$ Sin embargo, es de evidenciar que el país no es aún signatario del Convenio 169 de la OIT ${ }^{4}$ en el que se habla de los derechos de los pueblos indígenas y tribales, lo cual vendría a constituir una de las deudas más sobresalientes del Estado salvadoreño con este sector de la población.

\section{Multiculturalismo: un medio para tratar la diversidad cultural}

Como es sabido, en Latinoamérica la mayoría de Estados nación no son homogéneos sino multiculturales, pues en el seno de ellos conviven diversos grupos étnicos. Entre estos grupos, se calcula que más de 40 millones de personas son indígenas. Contrario a lo que ocurre en Guatemala, Perú, Ecuador o Bolivia, en El Salvador los indígenas son minoría. En efecto, el último censo de población y vivienda realizado en el 2007 muestra que solo un 0,02 \% desciende de los pueblos originarios (Dygestic, 2008). Por otra parte, es necesario advertir que hablar acerca de los indígenas en El Salvador es difícil y complejo. En las pláticas cotidianas y en el discurso de ciertos políticos se afirma que ya no hay indígenas en el país o que son grupos del pasado, y que solo han quedado como recuerdo en los libros, museos y ruinas arqueológicas (Ticas, 1998). A lo anterior hay que añadir que las investigaciones sobre los pueblos indígenas salvadoreños en la actualidad son escasas y las que existen requieren más rigor y profundidad.
Con base en esto, es un hecho y un reto la necesidad de abordar la diversidad cultural de un país. La realidad de que los indígenas sean minoría no es excusa para no tomarlos en cuenta. En ese sentido, el multiculturalismo es un concepto muy utilizado en diversos medios académicos; y hoy en día dicho término goza de mucha elaboración teórica. También, en las políticas públicas el multiculturalismo se utiliza como discurso para tratar la diversidad, sobre todo en países que tienen muchos grupos étnicos y culturales.

Al ir en búsqueda de los orígenes del multiculturalismo, Alvaro Bello dice que este concepto surgió en Canadá a mediados de los años sesenta con el objetivo de atender las problemáticas y demandas de los grupos inmigrantes, las minorías y los grupos étnicos. Este autor define así el multiculturalismo: "Por nuestra parte, entendemos el multiculturalismo como una realidad empírica y una forma de administrar las diferencias culturales en el interior de los Estados Nacionales" (Bello, 2004, p. 190).

A la luz de la cita anterior, se puede observar que el multiculturalismo se propone dar una respuesta a la diversidad cultural presente en muchos países. Por otro lado, a nivel teórico también han surgido varios autores que han hablado sobre las políticas del reconocimiento desde el punto de vista del multiculturalismo. Entre estos autores se encuentran Kymilcka y Charles Taylor. El primero afirma: "Las sociedades modernas tienen que hacer frente cada vez más a grupos minoritarios que exigen el reconocimiento de su identidad y la acomodación de sus diferencias culturales algo que a menudo se denomina el reto del multiculturalismo" (Kymilcka, 1996, p. 25).

Por su parte, Taylor, en un escrito, hablará de la importancia de las políticas del reconocimiento. En ese sentido mostrará que de los conceptos modernos de dignidad e identidad se ha iniciado lo que él denomina "la política del reconocimiento" y "la política de la diferencia". Así, con el concepto de dignidad dará comienzo la política del reconocimiento de la igualdad universal entre todos los seres humanos. A la vez, del concepto de identidad surgirá la política de la diferencia, es decir, que cada quien debe ser reconocido por su identidad única. Nos dice Taylor: "Solo concedemos

\footnotetext{
3 También es de señalar que existen ordenanzas en algunos municipios que establecen derechos de los grupos indígenas. Por ejemplo, resalta la "Ordenanza municipal sobre Derechos de las Comunidades Indígenas asentadas en el municipio de Nahuizalco", que apareció en el Diario Oficial el día 6 de julio de 2011.

${ }^{4}$ Este Convenio fue adoptado por la OIT en 1989 y entró en vigor en 1991. Hasta la fecha es el documento de derecho internacional sobre los indígenas más conocido en todo el mundo. Entre las críticas más fuertes a este documento es que no participaron los indígenas directamente en su realización. Los que lo formularon fueron sindicatos, gobiernos y parte de la empresa privada.
} 
el debido reconocimiento a lo que está universalmente presente - cada quien tiene una identidad - mediante el reconocimiento de lo que es peculiar a cada uno" (Taylor, 2009, p. 61).

También, Taylor enfatizará que el reconocimiento es algo fundamental tanto en la esfera privada como en la pública. De aquí que sea necesario reconocer a las diversas culturas y respaldarlo con normativas y leyes, entre otros instrumentos jurídicos.

Según lo que han dicho los anteriores autores, puede verse que el multiculturalismo es un intento teórico y político para tratar la diversidad de grupos sociales y culturales; y no se enfoca solamente en los pueblos originarios, sino que en esta postura se incluirían los inmigrantes, gitanos, homosexuales, etc. No se puede negar que el multiculturalismo ha tenido grandes conquistas, como por ejemplo, el lograr que muchas peticiones de los grupos minoritarios sean escuchadas y que sus demandas puedan ingresar a la legalidad y al Estado de derecho; también ha logrado bastante éxito en el campo de la educación. Sin embargo este concepto ha arrancado muchas críticas de diversos sectores.

\subsection{Críticas al multiculturalismo}

A pesar que el multiculturalismo tiene varios partidarios, también hay quienes lo han criticado duramente. Por cuestiones de espacio, en este trabajo se hará alusión solamente a dos críticas.

Unos autores, desde un análisis más marxista, opinan que el multiculturalismo es una construcción teórica favorable al neoliberalismo. Así, aunque el multiculturalismo tenga conciencia de la existencia de diversas etnias y de que es necesario reconocerlas y valorarlas, sin embargo, olvida las inequidades y asimetrías económicas y sociales presentes en toda sociedad. Al respecto Díaz Polanco afirma lo siguiente:

En tanto ideología del momento, diferencial del capital globalizador el multiculturalismo, exalta la diferencia como cuestión cultural mientras disuelve la desigualdad y la jerarquía que las mismas identidades diferenciadas contienen y que pugnan por expresar y superar. De ahí que acentúe la política del reconocimiento, mientras evita cualquier consideración o política respecto a la redistribución, cuya sola entrada denunciaría la desigualdad y apelaría a relaciones igualitarias... Este es el primer indicio de que el multiculturalismo es, ni más ni menos, que el enfoque y la política de la identidad del neoliberalismo globalizador (Díaz Polanco, 2006, p. 174).

Otra crítica que le han hecho a la propuesta del multiculturalismo es que, a juicio de varios autores, este concepto tiene como base y fundamento el liberalismo. De hecho, Kymilcka, con su ciudadanía multicultural, intenta responder a las preguntas ison compatibles los derechos individuales con los derechos colectivos?, ¿o será que se contraponen? En sus respuestas, Kymilcka afirma que son compatibles los derechos individuales con los colectivos, aunque siempre le dará preponderancia a los derechos individuales amparados en el paradigma liberal (Kymilcka, 1996, p. 56).

Díaz Polanco también será un férreo crítico del multiculturalismo. Nos dice al respecto: "El multiculturalismo liberal está dispuesto a aceptar cualquier grupo cultural que no desafíe la visión del mundo ni las prácticas que avalan el liberalismo" (Díaz Polanco, p. 178). Resulta interesante su crítica, pues pone en tela de juicio los alcances del multiculturalismo, puesto que, a pesar de que este término reconoce la existencia de otras culturas, en el fondo lo que quiere es arrastrarlas al paradigma liberal occidental.

A mi modo de ver, el problema del multiculturalismo (en varios autores, entre ellos Kymilcka) es que considera al paradigma liberal como la mejor manera de administrar las diferencias y, por tanto, pondrá la cultura occidental-liberal al centro y las otras culturas serán periféricas, debiendo estás últimas amoldarse a los principios, normativas e ideas del liberalismo. Esto sería injusto para las culturas y etnias indígenas, que tienen otro modo de ver la vida y están fuera del paradigma liberal. Y será justamente aquí donde se enmarca el término interculturalidad, que es lo que se verá a continuación.

\section{Interculturalidad: concepto alternativo al multiculturalismo}

Muchos teóricos, ante los problemas arriba mencionados que para ellos presentaba el multiculturalismo, van a acuñar otro concepto: interculturalidad. Xavier Albó la define así: "La interculturalidad se refiere sobre todo a las actitudes y relaciones de las personas o grupos 
humanos de una cultura con referencia a otro grupo cultural, a sus miembros o a otros rasgos y productos culturales" (Albó, 2000, p. 95). En efecto, algunos llegan a afirmar que el multiculturalismo fue un término acuñado en el primer mundo, específicamente en las naciones anglosajonas en donde existen minorías étnicas. Sin embargo, al aplicarlo a América Latina no funciona, pues es otra realidad y habrá ciertamente naciones en donde los grupos culturales son mayorías. Es por eso que, desde el ámbito latinoamericano, la interculturalidad será vista como la alternativa al multiculturalismo. Para ilustrar lo anterior, me parece muy sugerente una reflexión de Rigoberta Menchú, premio Nobel de la Paz de 1992, que cito a continuación:

La interculturalidad surge en el panorama del debate mundial como un mecanismo de comprensión y manejo de las relaciones entre culturas, que pretende salir de la atomización que han provocado las políticas multiculturalistas y evita caer en la trampa de los discursos asimilacionistas que predominaron después de la segunda guerra mundial (Nieto, 1999, p. 39).

Por tanto, la interculturalidad tiene como pretensión superar los discursos multiculturalistas que en el fondo no eran tan tolerantes con la diversidad cultural ya que en definitiva en el centro se tiene a una cultura que sería la occidentalliberal. De ahí que autores como Tapia hablen de hacer un núcleo común intercultural en donde ninguna cultura sea el fundamento sino que haya igualdad entre culturas. Nos dice lo siguiente:

En el núcleo común intercultural el objetivo es producir y reconocer igualdad entre pueblos y culturas... En este sentido, producir la igualdad política entre culturas implica pensar la configuración de un nuevo núcleo común, que tiene que ser deliberado, decidido, por los diferentes pueblos y culturas (Tapia, 2006, pp. 44-47).

Como puede verse en la cita anterior, Tapia es partidario de hacer un núcleo común intercultural en el que todas las culturas participen. Dicho núcleo no debe partir de la propiedad individual, como tradicionalmente se ha hecho, sino de lo comunitario. A la vez, es necesario reconocer varios derechos al entrar en contracto con otras culturas y no solo el derecho occidental-liberal. A criterio de Tapia, en este último punto habría que hacer una forma de gobierno que permita sustentar estos múltiples derechos.

4. Diálogo intercultural como mecanismo de solución a la discriminación y exclusión de los pueblos indígenas salvadoreños. Sus implicaciones éticas

En la parte final de este artículo se proponen soluciones a la realidad de discriminación e invisibilización histórica de los indígenas salvadoreños. Advierto que no pretendo agotar ni ser exhaustivo con el tema. Más bien, solamente se darán orientaciones de solución. La propuesta se hará teniendo en cuenta la filosofía de la interculturalidad y la ética de la vida propuesta por Enrique Dussel.

Raúl Fornet-Betancourt habló de una transformación intercultural de la filosofía que lleve a reconocer diversas racionalidades. Esto implicará aprender a dialogar con otras culturas que históricamente han sido negadas o marginadas (Fornet-Betancourt, 2001, p. 58). Este diálogo no brotará de la nada, sino que es necesario crear las condiciones para que estos pueblos puedan expresarse con voz propia (FornetBetancourt, 2001, p. 49). Por otra parte, siguiendo a Dussel, el horizonte de acción de un reconocimiento sobre los pueblos originarios tendría que ser una ética de la vida. Tal como lo afirma en uno de sus escritos, toda norma, institución o eticidad cultural tiene que partir de los excluidos, de las víctimas y debe tener como contenido último la producción, reproducción y desarrollo de la vida (Dussel, 1998, p. 40). De esta manera, si se tiene como perspectiva ética la afirmación rotunda de la vida humana, esto nos permitirá jerarquizar valores y fines. Así, toda política que tome en cuenta a los pueblos originarios debe garantizarles las condiciones mínimas, básicas y necesarias para que estos grupos puedan desenvolverse, crecer y manifestarse. Desde estas ideas, se podría decir que el compromiso del Estado salvadoreño hacia los pueblos originarios debería tener determinadas implicaciones éticas, como las siguientes:

a) Seguir reconociendo el legado de estas culturas originarias. Los pueblos originarios existían antes de que se formara la República de El Salvador e incluso antes de la colonización española. Esto conlleva a reconocer su aporte a la configuración de la nación y a valorar su riqueza cultural. De esta manera, unas implicaciones éticas fundamentales serían tanto seguir apoyando el conocimiento y difusión de estos grupos culturales como el rescate de la lengua náhuat. 
b) También es necesario que el Estado Salvadoreño ratifique el Convenio 169 de la OIT. De esa manera reconocería al menos formalmente la existencia de pueblos indígenas y se comprometería vinculantemente con estos grupos. Muy unido a esto, habría también la necesidad de promulgar leyes que beneficien a las minorías culturales, reconociéndoles el derecho a ser pueblo y, a la vez, dándoles derechos de territorio. Realizarlo sería hacer justicia a estos pueblos.

c) Sin embargo, no basta con reconocer jurídicamente a los indígenas salvadoreños. Hay que ir más allá. Y en esto es muy sugerente el paradigma intercultural. Bien dice Fornet Betancourt: "El interculturalismo plantea el problema no exclusivamente de reconocer la diversidad en un nivel retórico, sino el hacer el mundo de otra manera" (Fornet-Betancourt, 2005). De hecho, este mismo autor opina que muchas veces un instrumento jurídico puede ser herramienta propiciadora de la exclusión. Y aquí es donde entra lo vital de un diálogo intercultural entre las culturas indígenas y no indígenas; tendría como primer objetivo el conocimiento mutuo por el que se reconozcan las costumbres, diferencias, valores culturales, formas de gobierno, etc. Luego, se tendría que ver la necesidad de formar una nación incluyente, que escuche a los indígenas, vea sus necesidades y les de espacios y oportunidades para difundir sus ideas y pensamientos.

d) El diálogo intercultural también llevaría a tomar acciones para crear las condiciones básicas para que estos pueblos puedan organizarse y desarrollarse. Desde este punto de vista, es responsabilidad del Estado garantizar protección a estos grupos. Desde otro punto de vista, ayudaría a que los pueblos originarios puedan participar activa y directamente de las decisiones del Estado. Sobre esto, una de las críticas que se le hace al Convenio 169 de la OIT es que los grupos indígenas no participaron directamente en su elaboración. En un diálogo intercultural, ellos, aparte de ser escuchados, también tendrían participación directa en las decisiones y en la redacción de documentos vinculantes. ${ }^{5}$
Lo anterior es difícil, ya que hasta el momento en el país no se escuchan muchas propuestas multiculturalistas ni interculturalistas. Por tanto, realizar un diálogo intercultural implicaría un largo proceso que tendría que empezar por un cambio de mentalidad en muchos políticos e intelectuales salvadoreños, pues todavía son muy fuertes las visiones monoculturales y de homogenización del Estado nación salvadoreño. Sin duda, realizar un diálogo intercultural nos puede llevar a otras implicaciones éticas, tales como reconocer la alteridad y la necesidad de responsabilizarnos.

\section{Referencias}

Albó, X. (2000). Iguales pero diferentes: hacia unas políticas interculturales y lingüísticas para Bolivia, S.P.I. La Paz, Bolivia.

Bello, Álvaro (2004). Etnicidad y ciudadanía en América Latina .La acción colectiva de los pueblos indígenas. Cepal, NacionesUnidas, GTZ, Santiago de Chile.

Casaús Arzú, Marta (2010). Guatemala: linaje y racismo, F\&G Editores, Guatemala.

Concultura et al. (2003). Perfil de los pueblos indígenas de El Salvador, Ministerio de Educación, San Salvador.

Cortez Tejada (2016). El concepto de indio a lo largo de la historia en El Salvador, en Revista Identidades, año 6, n. ${ }^{\circ} 10$, San Salvador.

Digestyc (2008). Censo de población y vivienda 2007, San Salvador, El Salvador.

Díaz-Polanco, Héctor (2006). Elogio de la diversidad, Siglo XXI, México.

Fornet-Betancourt, Raúl (2001). Transformación intercultural de la filosofía, Desclée de Brouwer, Bilbado.

Fornet-Betancourt, Raúl (2005). Ponencia en el I/ Congreso de Filosofía "Xavier Zubiri", San Salvador, El Salvador.

Kyimilcka (2009). Ciudadanía multicultural, una teoría liberal del derecho de las minorías, Paidós.

Lemus, J. (2011). "Una aproximación a la definición del indígena salvadoreño", en Revista Científica, n. ${ }^{\circ} 12$, Universidad Don Bosco, San Salvador.

Martínez, R. (2012). "El genocidio cultural de 1932 narrativas y memorias de la represión", Tesis de Maestría en Filosofía Iberoamericana, San Salvador, El Salvador.

Nieto Montesinos, J. [Compilador] (1999). Sociedades multiculturales y democracias en América Latina, Unesco, México

\footnotetext{
5 De hecho, en otros países existe una etno-educación y unos bilingüismos educativos. Resalta el caso de Paraguay, en donde la reforma educativa manifiesta que los programas educativos se hicieran en castellano y guaraní.
} 
Rodríguez González, Javier (2003). León bajo la dictadura franquista, Universidad de León, España.

Serres, M. 1991. Los orígenes de la geometría. México: Siglo XXI. Stavenhagen Rodolfo (1999). "Derechos humanos y ciudadanía multicultural, los pueblos indígenas", en
Sociedades multiculturales y democracias en América Latina, Montesinos, N. (Compilador), Unesco, México. Stavenhagen, Rodolfo (2010). Los pueblos originarios: el debate necesario. Instituto de Estudios y Formación de la CTA, Buenos Aries, Argentina. 